\title{
The Status of RS/GIS/GPS Applications in Sri Lanka A Survey of Public, Private and Non Governmental Organisations
}

\author{
N. T. S. Wijesekera and T. Chandana Peiris
}

\begin{abstract}
The modern technology and its tools namely GIS, GPS and Remote Sensing are widely used for planning and management of cities, land use, planning and management of utilities and resources, multipurpose cadastre, e-government, e-municipality, e-commerce and for decision making with respect to the management of many other resource management systems. In most of the developing countries the spatial databases and related information systems have been in place and the associated technologies have been set in place. In case of Sri Lanka spatial resource management had been recognized as very important by many decision makers and as a result attempts have been made to incorporate necessary infrastructure in work places. The present work describes a survey of the present Geoinformatics applications and resource usage status through a questionnaire circulated among organization to capture data to assess the overall scenario corresponding to the Geoinformatics applications. The questionnaire was sent to a total of 67 known public, private and non governmental sector organizations which are carrying out Geoinformatics applications. Survey data were analysed in relation to four indicators collectively representing the overall strength of Geoinformatics Application Status (GAS), of a particular organization. The four component indicators represent the status of an organizations commitment, readiness, competence and the work experience, related to informations applications.
\end{abstract}

Key Words: Geoinformatics, Status, Sri Lanka, Indicators, , Commitment, Readiness, Competence, Experience

\section{Introduction}

Geoinformatics applications vary from managing natural resources of over tens or hundreds of thousands of acres of land, identification of urban sprawl in the cities and surroundings, identification of human resource mobilization over large and difficult to access terrain, for national security, identification of crop growth, assessment of floods and flood losses, housing construction, monitoring of Tsunami damage and recovery over long coastal strips etc.

The availability of aerial photographs and satellite imagery has improved efforts to manage natural resources. GPS has a tremendous impact on the identification of positions where resource mobilization has to be done or to locate where critical features exist. The biggest benefit of GPS technology is that it enables the identification of distribution patterns or changes to geographic features. GIS, Remote Sensing and GPS combined as Geoinformatics (Wikipedia 2008) have enabled many decision makers and their supporting staff to study different alternatives or options for resource management with relative ease, less cost and reasonable effort. In the developed world where resource management is considered as a very competitive affair, Geoinformatics applications is being widely used in almost all sectors ( ESRI 2008, Yeung and Lo 2005, Rhind et al 2001). The application of Geoinformatics for resource management does not have a long history. The science of Geospatial Information Science which is a very recent development has gathered momentum in the early 1990s. In the U.S Geological Survey (USGS), which has a long history in the development of geospatial data, a center of excellence for Geospatial Information Science was initiated only in the year 2006 (NAS 2007). Having identified the importance of the use of geographic information science, the National Research Council of USA, has made recommendations to incorporate GIS as a

Professor N.T.Sohan Wijesekera B.Sc.Eng. Hons.(SriLanka), PG.Dip (Moratuwa), M.Eng.(Tokyo),D.Eng. (Tokyo), MlCE(UK), FJE(SL), Chartered Civil Engineer, Professor, Department of Civil Engineering, University of Moratuwa, Katubedda, Moratuwa, Sri Lanka.

Mr. T. ChandanaPeiris B.Sc. (Colombo), M. Tec (India), Nat. Dip. Eng. Sc. (Sri Lanka), PG. Dip. Applied Electronics (Colombo), MIET, Research Scientist, Arthur C Clarke Institutefor Modern Technologies, Katubedda, Moratuwa, Sri Lanka. 
support system in the K-12 Curriculum (NAS 2006). The Government of Sri Lanka has also recognized the need and has initiated action to develolp a policy on spatial data use (MNBEID 2008).

Though the strength of Geoinformatics has been identified, the practice needs several components to be in place for efficient use of the tools. Availability of qualified and experienced resource personnel, adequate hardware and software, experience in applications and an enabling environment are the key components that require to be in place for such action.

\section{Objective of the Study}

The objective of the present work is to carryout a survey of Sri Lankan organizations that are associated with Geoinformatics applications and to analyse the present situation in order to identify suitable indicators leading to the enhancement of the effective use of Geoinformatics applications in Sri Lanka.

\section{Literature Review}

\subsection{Status Identification}

Recent literature cites several studies pertaining to the practice of Geoinformatics in Sri Lanka. De Silva (2002), Dayawansa and De Silva (2005), Wijesekera (2005), Bandara (2005) and Jayatilaka (2005) have discussed main issues such as 1) Experience and practice, 2) RS/GIS in the Education Curricula, 3) Common software, 4) Availability of infrastructure and hardware, 5) Data Sharing and Standards, 6) Application possibilities, 7) Requirements of on the job training, 8) Lack of a National Policy on spatial data infrastructure, 9) Sustainability of Geoinformatics technology in the respective organizations and 10) recommendations on the way forward. Wijesekera (2005) based on the survey of practicing agencies had identified the existence of approximately 22 divisions of Sri Lankan agencies that were practicing Geoinformatics. The estimated number of persons practicing various components of Geoinformatics in the year 2005 had been counted as approximately 116 graduates and 117 non-graduates. List of projects carried out by the agencies had been approximately 53 .
The Ministry of Nation Building and Estate Infrastructure Development, and the Ministry of Land and Land Development through an advertisement that appeared in the newspaper Daily News on 9th June 2008, sought public comments on a draft national policy on Spatial Data Use (MNBEID 2008). The draft policy includes policy considerations on, data standards, copyright, pricing, security, promotion of the use in planning and education, data integration, establishment of a national information center, and the policy implementation through a national steering committee. Wijesekera (2008) in a connected document has indicated the possibility of improving the draft policy document and has stressed the need to ensure a comprehensive, overarching national spatial data infrastructure giving due consideration to national security.

\subsection{Status Indicators}

In case of an assessment of a status, it is important to have a measure or a combination of measures called indicators that would provide information on the current situation pertaining to a set of objectives. Indicators not only enable the evaluation of the performance in relation to a set of objectives, they guide the planning of services or activities, support decision making and enhances operational performance (Menou 1993). Menou (1993) and the UNESCO publication on "Developing and Using Indicators of ICT Use in Education" provides a comprehensive guide with regards to the use of indicators for impact assessments, need and rationale to use, types of indicators and those used in various places, characteristics of indicators and the methods of collecting indicators. US Public-Sector Survey: Key Issues and Trends (Gartner 2002) in its summary, points to several important areas that need to be considered when attempting to develop indicators for a status assessment. Such areas highlighted in Gartner (2002) include the respondent distribution, infrastructure, hosting and management, governance, data and standards, vendor issues, software and hardware, staffing, finances etc.

\section{Methodology}

Assessment of the status of RS/GIS/GPS applications in Sri Lanka was carried out with 
the direction of Arthur C Clarke Institute for Modern Technologies (ACCIMT). Based on the literature survey and giving due consideration to the issues of data collection from various agencies, a questionnaire survey was undertaken to capture Geoinformatics application status at various agencies involved in the practice of Geoinformatics. Overall methodology adopted for the study is shown in Figure 1.

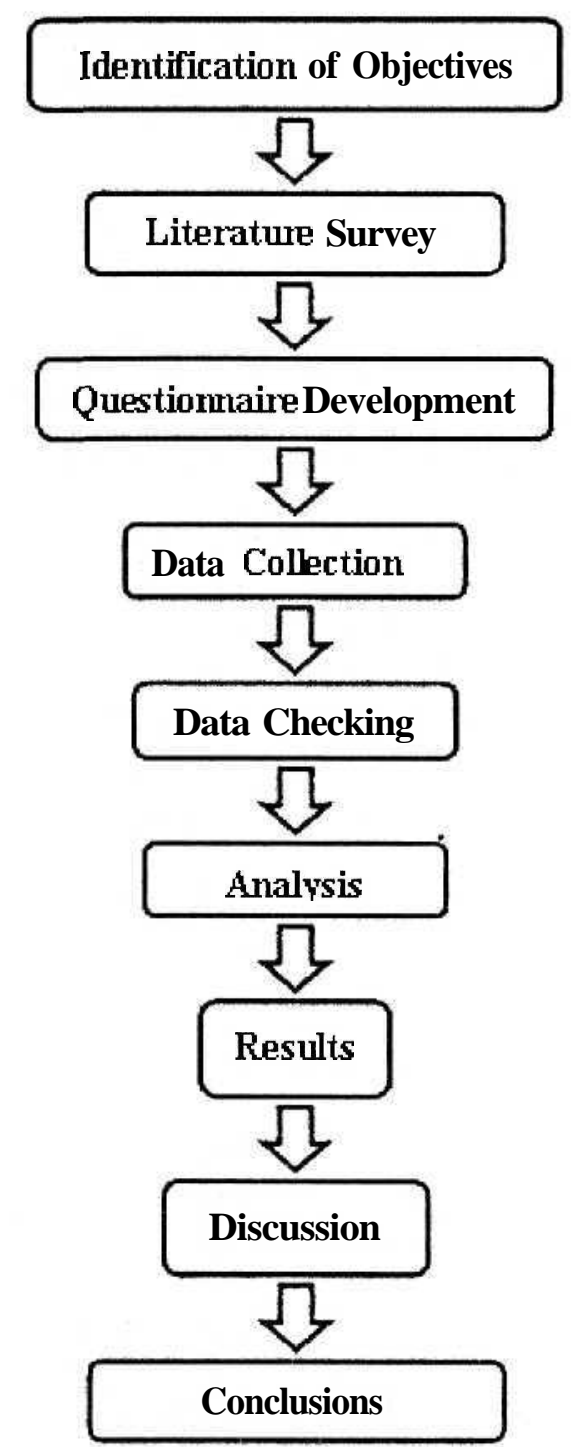

Figure1: Overall Methodology of the Study

Based on the literature indications, the present study identified four key areas to be assessed using the data collected at the survey. They were, the need to capture the "Commitment" extended by the management of respective agencies, the "Readiness" of an agency to carryout Geoinformatics applications, the "Competence" of an agency to perform activities related to Geoinformatics, and the available "Experience" pertaining to carrying out applications.

Arthur C Clarke Institute for Modern Technologies, of the Ministry of Science and Technology, is the National Focal Point (NFP) of the Regional Space Applications Programme (RESAP) of United Nations. The United Nations in their 2006 country inventory preparation programme, utilized a questionnaire (UNESO 2006). Main structure of the questionnaire for this status survey was developed similar to the UN inventory questionnaire. The questionnaire consisted of data capture questions in the areas shown in Table 1. Space was provided to obtain specific answers to each area either with the use

Table 1: Data Capture Areas in the Questionnaire

General

- Name of Organisation

- Type of Organisation

- Major Tasks carried out

- Sector of Operation

- Kind ofApplications Carried out

- Availability of a Separate Division or Unit Year of commencement of a Separate Unit Location of the office

Attached to head office or to a regional office

- Availability of an employee to use as a Resource Person in case of no Separate Division

- Availability of employees Interested in GeoinformaticsApplications

- Availability of an External Resource Person for Geoinformatics

- Availability of an Annual Budget Allocation for Geoinformatics

- Membership of Geoinformatics Related Regional and International organizations

\section{Human Resources}

- Highest Ranking Officer In Charge ofRS/GIS Activities:

- Number of Professional Staff: and Corresponding Qualifications

- Number of Professional Staff: with Practical Experience

- Number of Professional Staff: having at least Two Weeks Structured Training

Facilities

- Software Availability: Type and Number of Units

- Availability of Equipment and Machinery:Type, and Number of Units

Projects and Training Executed

- Major Projects

- Major International / Regional Seminars, Conferences and Workshops

- Earth Observation Satellite Applications 
of structured Tables to input data, or through guided answers to be selected by a respondent. Data capturing forms made provisions to separately capture the details corresponding to GIS, Remote Sensing and GPS.

Questionnaire development was systematically carried out with the incorporation of modifications after carrying out several sample data filling efforts. The questionnaire was designed to capture data through mail and hence a covering letter to the heads of each organization explaining the objectives of the survey was included.

Data captured through the questionnaire was tabulated and then were ranked using a qualitative classification having four class groups identified as Threshold (Very High), High, Medium and Low. The qualitative classification of the quantitative data captured by the questionnaire was judgmental. The status identified at the last survey (Wijesekera 2005), and on the job experiences were also utilized for the assessment of each component. Each class was then assigned a numerical value as 5, 3, 2, and 1, respectively for Threshold, High, Medium and Low. This was to enable the identification of corresponding percentage indicators ranging from $0-100 \%$. Qualitative assessments were initially carried out utilizing a research assistant and were then verified to identify the acceptability of the assessments.

Threshold (Very High) status was defined as the level of achievement expected of an organization to carryout a particular task ensuring the standard desired in comparison with the status of execution of that task by a majority of international icon agencies. In the literature survey it was noted that presently our nation is in the process of recognizing a policy, formulating regulations, identifying mechanisms for data pricing and data quality, providing commitment to agencies etc. Therefore a wider margin was allocated for the region allocated for the Threshold status so that it would reflect the need of the country to accomplish these critical factors that are essential for effective and efficient decision making. The high, medium and low classes were allocated to represent the status achieved in relation to the lower boundary of the Threshold status. Table 2 presents the qualitative classification, numerical representations and the corresponding percentages along with their descriptions.

The questionnaire data fields making partial contributions to each of the four identified indicators, were grouped to compute each indicator. The tabulations enabled the assigning of weights to sub components where necessary. Each indicator, the lower bound of the threshold status identifier and the basis for qualitative classification of the data field are shown in the Table 3.

Contributing sub factors for each indicator were aggregated to compute the overall value for that indicator. In computations, the status with respect to GIS, RS and GPS were computed separately. In the case of sub factors which were

Table 2: Qualitative Classes and Corresponding Details of Status

\begin{tabular}{|l|c|c|c|}
\hline $\begin{array}{c}\text { Qualitative } \\
\text { Classification of } \\
\text { Status }\end{array}$ & $\begin{array}{c}\text { Numerical } \\
\text { Representation }\end{array}$ & $\begin{array}{c}\text { Corresponding } \\
\text { Range Percentage } \\
\text { Value for the Range }\end{array}$ & \multicolumn{1}{c|}{ Classification Description } \\
\hline $\begin{array}{l}\text { Threshold } \\
\text { (Very High) }\end{array}$ & $2-5$ & $60 \%-100 \%$ & $\begin{array}{l}\text { An Organization reaching the upper } \\
\text { bound status is assumed to have reached } \\
\text { excellent status with respect to both } \\
\text { Quality and Quantity } \\
\text { Indicates that an Organisation has } \\
\text { achieved a high status compared to the } \\
\text { Threshold } \\
\text { Indicates that an Organisation has } \\
\text { achieved a Moderate status compared to } \\
\text { the Threshold } \\
\text { Indicates that an Organisation has } \\
\text { achieved only a Low status compared to } \\
\text { the Threshold }\end{array}$ \\
\hline
\end{tabular}


Table 3: Description of Lower Bound of the Threshold Status and Classification Basis of Each Indicator

\begin{tabular}{|c|c|c|c|}
\hline \multirow{10}{*}{ 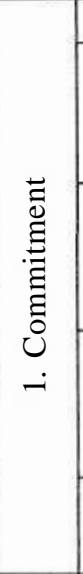 } & Threshold Status - Lower Bound & & Basis for Classification of Data Field \\
\hline & \multirow{2}{*}{$\begin{array}{l}\text { Organization has indentified the importance of } \\
\text { Geoinformatics and given due infrastructure } \\
\text { sipport in terms of divisions and finances }\end{array}$} & 1.1 & Dedicated Financial Support for Geoinformatics \\
\hline & & 1.2 & $\begin{array}{l}\text { Avilability of a Dedicated Division for } \\
\text { Geoinformatics }\end{array}$ \\
\hline & \multirow{3}{*}{$\begin{array}{l}\text { Organization has enabled the acquisition of } \\
\text { suitable software in adequate numbers }\end{array}$} & 1.3 & Software Availability - GIS \\
\hline & & 1.4 & Software Availability - RS \\
\hline & & 1.5 & Software Availability - GPS \\
\hline & \multirow{3}{*}{$\begin{array}{l}\text { Early recognition of importance of } \\
\text { Geoinfomatics by the Organization }\end{array}$} & 1.6 & Early Organizational Commitment for GIS \\
\hline & & 1.7 & Early O rg anizatiana 1 Commitment for RS \\
\hline & & 1.8 & Early Organizational Commitment for GPS \\
\hline & $\begin{array}{l}\text { Recognition of need for quality; and necessity } \\
\text { of supervised strengthening }\end{array}$ & 1.9 & Availability of Geoinformatics Resource person \\
\hline \multirow{13}{*}{ 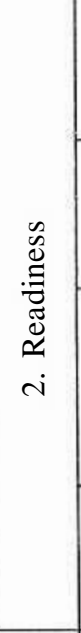 } & \multirow{3}{*}{$\begin{array}{l}\text { Expression of Enthusiasm and ability to face the } \\
\text { challenge to carryoutGeoinformatics Applications }\end{array}$} & 2.1 & Present Involvement-GIS \\
\hline & & 2.2 & Present Involvement-RS \\
\hline & & 2.3 & Pre se nt Involve me nt-GPS \\
\hline & \multirow[t]{3}{*}{ Indication of Capability to Execute Specific Tasks } & 2.4 & GIS, and RS Map Making \\
\hline & & 2.5 & GIS and RS Analysis \\
\hline & & 2.6 & GIS and RS M ode ling \\
\hline & \multirow{4}{*}{$\begin{array}{l}\text { Availability of Suitable Infrastructure Capabilities } \\
\text { to Commence Geoinformatics Applications }\end{array}$} & 2.7 & Equipment Availability-Computers \\
\hline & & 2.8 & Equipment Availability-Scanners, Digitizers \\
\hline & & 2.9 & Equipment Availability-Plotters \\
\hline & & 2.10 & Equipment Availability-GPS \\
\hline & \multirow{3}{*}{$\begin{array}{l}\text { Allocation of a Satisfactory Level of Staff both in } \\
\text { Standard and Numbers }\end{array}$} & 2.11 & Availability of Capable Staff GIS \\
\hline & & 2.12 & Availability of Capable Staff RS \\
\hline & & 2.13 & Availability of Capable Staff GPS \\
\hline \multirow{7}{*}{ 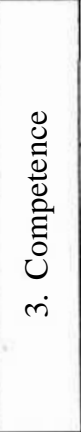 } & \multirow{3}{*}{$\begin{array}{l}\text { Availability of Sufficient Staff Numbers who } \\
\text { have Received Structured Training in } \\
\text { Geoinformatics Applications }\end{array}$} & 3.1 & Staff Trained Specifically in GIS \\
\hline & & 3.2 & Staff Trained Specifically in RS \\
\hline & & 3.3 & Staff Trained Specifically in GPS \\
\hline & \multirow{3}{*}{$\begin{array}{l}\text { Availability of Adequate Staff Numbers who } \\
\text { have Received Supervised on the job Training }\end{array}$} & 3.4 & On the Job Trained Staff-GIS \\
\hline & & 3.5 & On the Job Trained Staff-RS \\
\hline & & 3.6 & On the Job Trained Staff-GPS \\
\hline & $\begin{array}{l}\text { Possession of Suitably Competent persons to } \\
\text { capture and carryout structured, challenging } \\
\text { Geoinformatics Applications }\end{array}$ & 3.7 & $\begin{array}{l}\text { Availability of PhD,. MSc and BSc Qualified } \\
\text { Staff }\end{array}$ \\
\hline \multirow{7}{*}{ 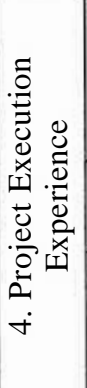 } & \multirow{3}{*}{$\begin{array}{l}\text { Demonstration of Quality Project Experiences } \\
\text { through the Generation of Scientific } \\
\text { Publications and Reports, and the Number of } \\
\text { Projects Executed }\end{array}$} & 4.1 & Publications and Reports on Projects - GIS \\
\hline & & 4.2 & Publications and Reports on Projects - RS \\
\hline & & 4.3 & Publications and Reports an Pro je cts -GPS \\
\hline & $\begin{array}{l}\text { Demonstration of Competence in Executing } \\
\text { International, Regional Projects }\end{array}$ & 4.4 & $\begin{array}{l}\text { International, Regional, National Project } \\
\text { Experience }\end{array}$ \\
\hline & \multirow{3}{*}{$\begin{array}{l}\text { Demonstration of Capability to Train, and } \\
\text { Teaching Competence in Different Kinds of } \\
\text { Geoinformatics Applications }\end{array}$} & 4.6 & Training Programs-GIS \\
\hline & & 4.7 & Training programs - RS \\
\hline & & & Training Programs - GPS \\
\hline
\end{tabular}

reflecting a combined influence were evenly apportioned to assign a value for GIS, RS and GPS. Once GIS, RS and GPS components were calculated then those values were added to compute the overall indicators pertaining to Commitment, Readiness, Competence and
Projects Experience. In the conceptual model computations, each sub component were given equal weight except for two factors, namely the i) and ii) which were a given weightage of 2 compared to the 1 assigned to others. These special weights were assigned to reflect the need 
to have academically competent persons for acceptable competence, and the need to have international exposure to be capable of responsibly handling Geoinformatics projects. Indicator values corresponding to each component were added to identify the overall status indicator of a particular organization. These values were then normalized by the maximum possible score, to compute the percentages for each component ensuring conditions of mutual compatibility and the relative representativeness (Menou 1993).

\section{Data, Collection and Checking}

The questionnaire was posted to 67 agencies that were reported as agencies carrying out Geoinformatics applications. These agencies included Universities, Public, Private, and Non Governmental organizations. The filled questionnaires were collected using one of the three following methods namely, by post, through fax or by visiting the respective agencies.

Since some organizations had several units actively contributing to Geoinformatics applications, a total of 86 questionnaires were sent to the 67 agencies. The data collection consumed a significant time and effort and the data collection support given by the ACCIMT had recorded a significant number of telephone reminders to various agencies. Five agencies were physically visited to collect the filled questionnaire. Data collection efforts of ACCIMT are shown in the Table 4. All collected data were subjected to a careful check prior to entering into a digital database. There was only one agency which had submitted

Table 4: Summary of Data Collection Effort by ACCIMT

\begin{tabular}{|c|c|}
\hline Description & Number \\
\hline 1 Agencies Contacted for Data Collection & 67 \\
\hline 2 Agency Responses without Reminders & $\mathbf{1}$ \\
\hline 3 Agency Responses with Reminders & 37 \\
\hline 4 Telecommunication Reminders & 108 \\
\hline 5 Agency Visits for Data Collection & 5 \\
\hline $\begin{array}{l}6 \text { No Agency response even after } \\
\text { repeated requests }\end{array}$ & 30 \\
\hline $\begin{array}{l}7 \text { Agency responses indicating no } \\
\text { Relevance }\end{array}$ & 2 \\
\hline $\begin{array}{l}8 \text { Agency Response indicating repeated } \\
\text { request }\end{array}$ & 1 \\
\hline
\end{tabular}

duplicate data under different names and it was corrected. The data collected were pertaining to 16 academic, research or training organizations, 20 corresponding to executing or regulating agencies and two from software vendors. The questionnaire survey commenced in April 2008 and ended in June 2008. It is to be noted that five of the known Geoinformatics practitioner agencies which had participated in the survey in 2005 had been omitted from the survey due to an oversight.

\section{Results}

\subsection{Agency Type and Activities}

Agency responses to the survey is shown in the Figure 2 and Table 5. The Academic institutions that were carrying out Geoinformatics applications totaled to $39 \%$ of those responded. Whereas the government and semi governmental agencies totaled to $24 \%$ each. Major activities carried out by various agencies are shown in the Figure 3. $25 \%$ of the agencies are carrying out Geoinformatics for research purposes, $19 \%$ of the agencies are involved in academic activities, $11 \%$ are carrying out tasks associated with planning, $10 \%$ are involved in consultancy activities.

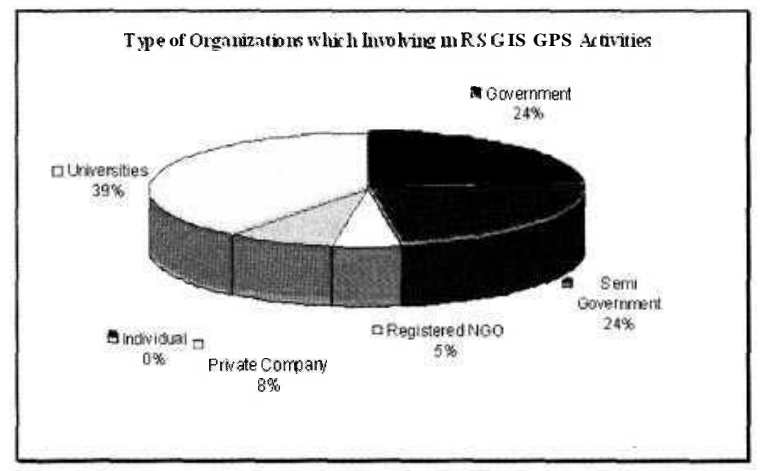

Figure 2 : Agency Responses to the Questionnaire Survey

Table 5: Summary of Data Collection Effort by ACCIMT

\begin{tabular}{|ll|c|}
\hline \multicolumn{1}{|c|}{$\begin{array}{c}\text { Type of Organization/ } \\
\text { Unit }\end{array}$} & $\begin{array}{c}\text { Number Carrying out } \\
\text { Geoinformatics } \\
\text { Applications }\end{array}$ \\
\hline 1 & Government & 9 \\
2 & Semi Government & 9 \\
3 & Registered NGO & 2 \\
4 & Private Company & 3 \\
5 & Individual & - \\
6 & Universities/Academic & 15 \\
\hline
\end{tabular}




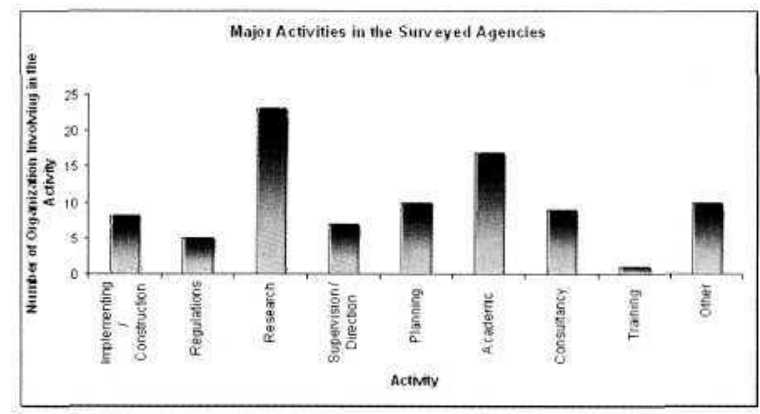

Figure 3; Major Activities carried out by Surveyed Agencies

\subsection{Sector Coverage and Capability}

The sector coverage by agencies carrying out Geoinformatics applications are shown in the Table 6. Education sector is the sector that has most agencies practicing Geoinformatics. The agency capabilities in terms of GIS, RS and GPS are shown in the Figure 4. The highest use is by

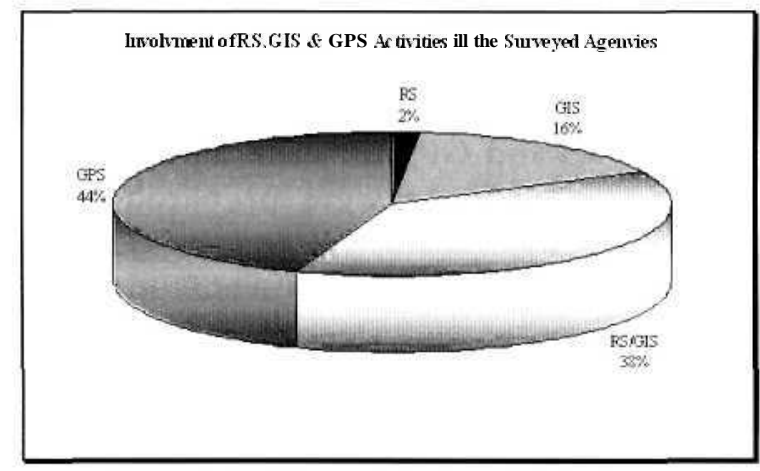

Figure 4: GIS, RS and GPS Activities in the Surveyed Agencies
GIS users. They total to $54 \%$ of the community. Next highest is the GPS with $44 \%$. Remote Sensing users also account to approximately $40 \%$.

\subsection{Geoinformatics Tasks}

The Geoinformatics tasks carriedout by agencies are mostly for database preparation or for map creation. $23 \%$ of surveyed agencies fall into this category. $19 \%$ of the agencies carryout Image analysis while Spatial Analysis is done by $17 \%$.

\subsection{Software and Personnel}

Geoinformatics Software use in the surveyed agencies is shown in the Figure 6. Mostly used softwareis the ESRI ArcGIS with a market share of approximately $29 \%$ and another $25 \%$ are using ESRI ArcView software. The software ILWIS has shown approximately $13 \%$ of the software share among the surveyed agencies.

The number of personnel engaged in Geoinformatics applications at the surveyed agencies is shown in the Figure 7. The total number in all categories total to 1286 . The majority are GPS users. It appears that the number of persons in the GIS and RS fields and especially trained persons are very less.

Table 6: Summary of Data Collection Effort by ACCIMT

\begin{tabular}{|l|c|l|c|}
\hline \multicolumn{1}{|c|}{ Field } & Number & \multicolumn{1}{c|}{ Field } & Number \\
\hline Agriculture & 7 & Livestock development & 1 \\
Air Transport & - & Labour \& Vocational Training & - \\
Balance of Payment & - & Media & 1 \\
Cultural & 2 & Management \& Institutional Development & 2 \\
Construction & 2 & Industrial Development & 1 \\
Defence & 7 & Mining \& Quarrying & 2 \\
Power \& Energy & 1 & Plantation & 5 \\
Education & 16 & Ports \& Shipping & 1 \\
Environmental Infrastructure & 7 & Rehabilitation & 2 \\
Food & 1 & Rural Development & 3 \\
Finance \& Banking & - & Youth \& Sports & 1 \\
Fisheries \& Aquatics & 2 & Scientific research & 11 \\
Forestry & 1 & Social Welfare & 1 \\
Ground Transport & $\mathbf{1}$ & Trade & 1 \\
Health & - & Ports \& Telecommunication & - \\
Housing \& Urban Development & 4 & Tourism \& Hotel & 2 \\
Private sector Development & 2 & General & 1 \\
Irrigation & 5 & Others & 7 \\
Land Development & 9 & & 1 \\
\hline
\end{tabular}




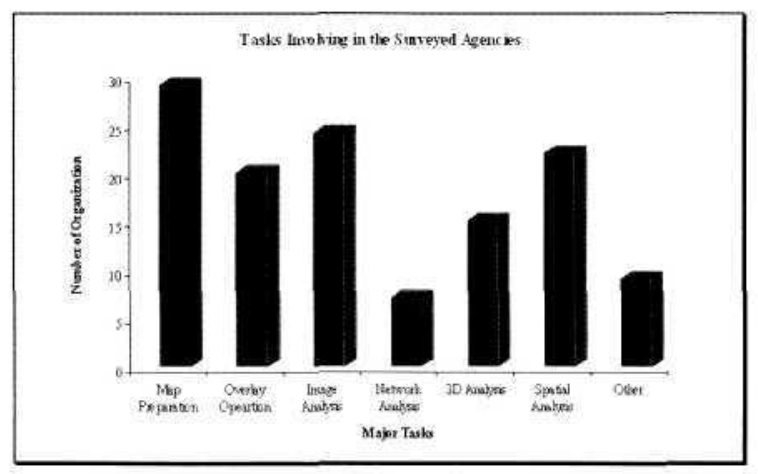

Figure 5: GeoinformaticsTsk carried out by Sirveyed Agncies

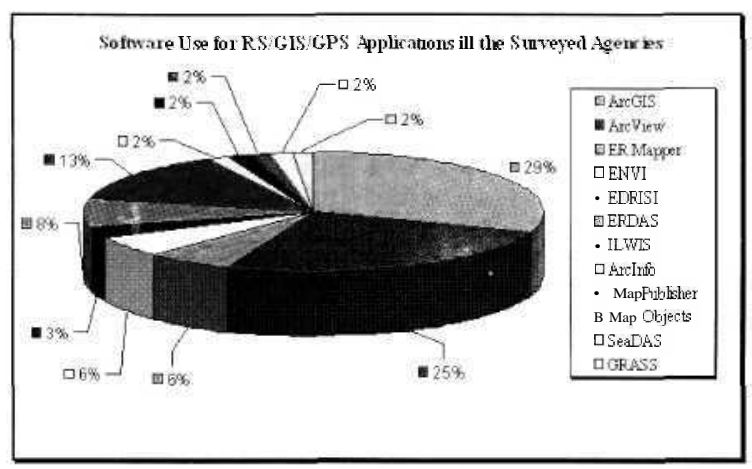

Figure 6: RS, GIS \& GPS Software Usefor Geoinformatics Applications

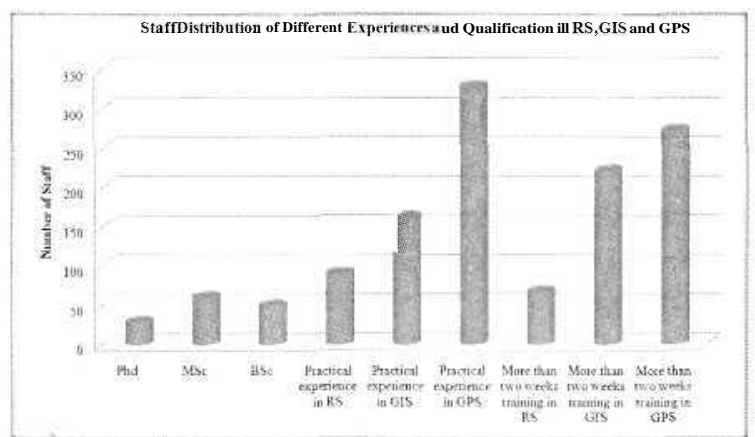

Figure 7: Various Types of Staff Carrying out Geoinformatics Applications

\subsection{Separate Divisions and Budgets}

Survey results indicated that only a few agencies have recognized a separate division for Geoinformatics activities. However an increasing trend could be observed in the recognition of separate divisions within surveyed agencies. This is shown in the Figure 8. Out of the surveyed agencies, only 9 agencies (24\%) had been given a separate budget allocation for their activities in RS, GIS and GPS. 29 organizations $(76 \%)$ had carried out their activities without a separate budget allocation.

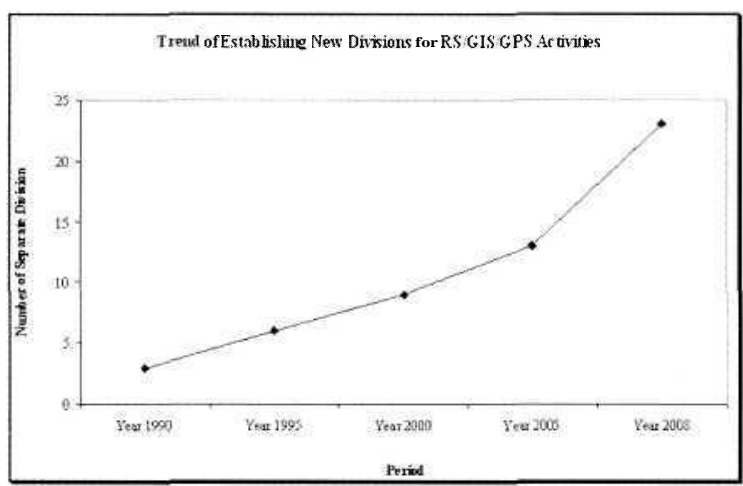

Figure 8: Trend of Establishing New Divisions for Geoinformatics

\subsection{Indicator Variation}

Indicator values for the four components namely commitment, readiness, competence and experience were computed for all responded agencies except for two vendor organizations because the level of Geoinformatics application of the vender organizations did not reach a meaningful level with respect to the others. The values computed for GIS, RS and GPS for each agency were stacked and graphs were prepared for a comparative assessment. The Figures 9-12 show the components whereas the overall indicator value named as the Overall Indicator for Geoinformatics Applications Strength (GAS) is

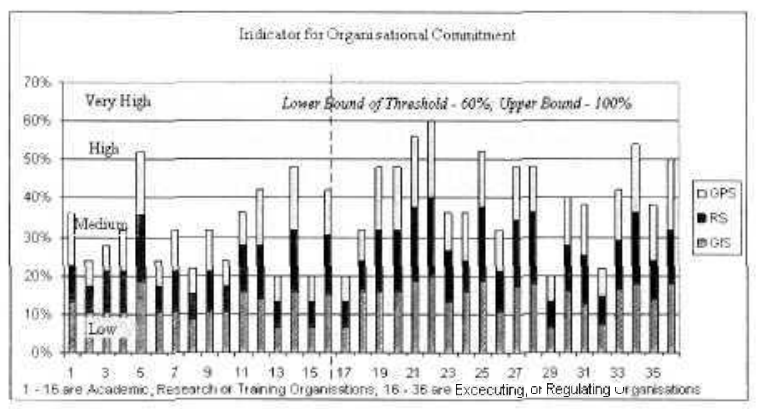

Figure 9: Organizational Commitment towards Geoinformatics Applications

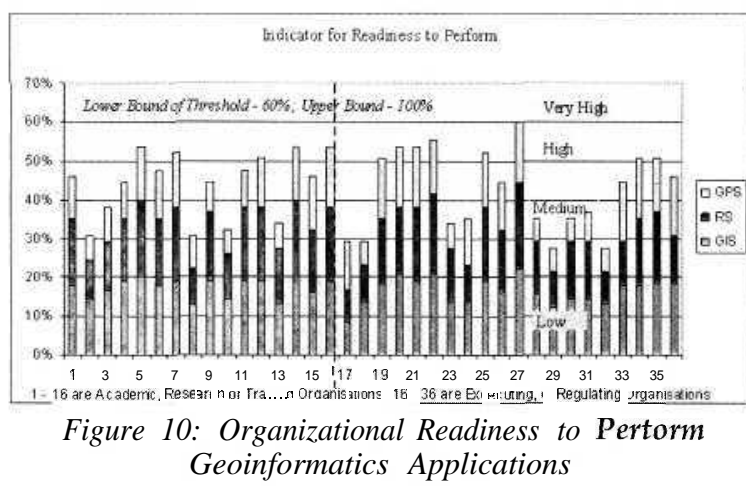




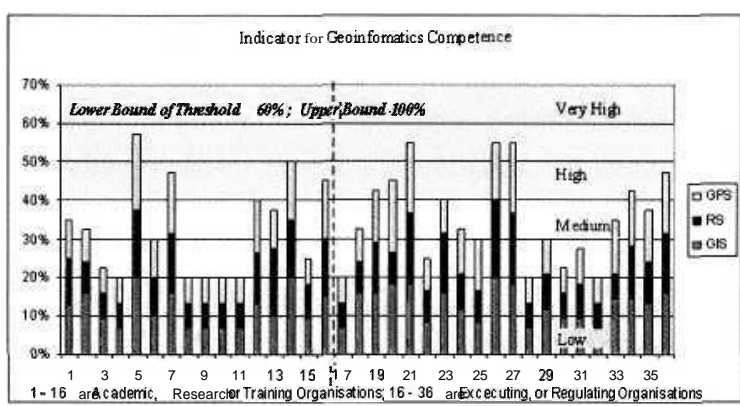

figure 11: Organizational Competence to Carryout Geoinformatics Applications

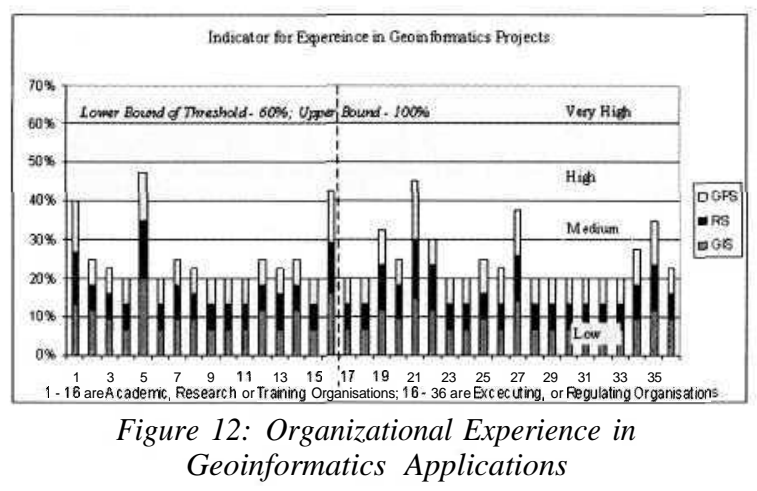

shown in the Figure 13. GAS values indicate that only three agencies have reached a level of high with an indicator value greater than $50 \%$. Another 11 have reached a value above $40 \%$ indicating that approximately $40 \%$ of the agencies only have reached a high level when compared with the expected threshold limits.

\section{Discussion}

\subsection{Summary Statistics}

1. Survey results have indicated an increased number of agencies carrying out Geoinformatics applications when compared with the survey carried out in 2005 . This shows an increase of approximately $75 \%$ by

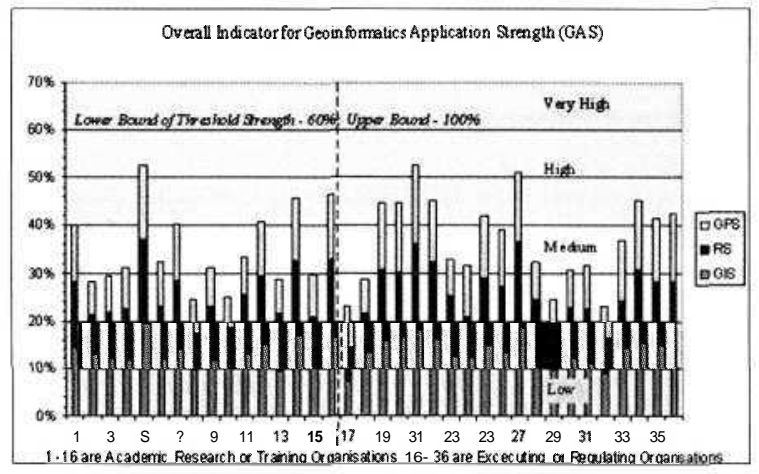

Figure 13: Overall indicator of Strength in Geoinformatics Applications the year 2008. Number of agencies engaged in Geoinformatics is very small compared to the country's total number of agencies that could be using Geoinformatics for the execution of respective duties. This may be due to the lack of awareness among the potential users on the potential use of Geoinformatics and a lack of trained staff who could demonstrate Geoinformatics project executions. The absence of data pertaining to several major agencies known to practice Geoinformatics also should be considered when interpreting the results for practical use.

2. The distribution of agencies carrying out Geoinformatics applications (Figure 2, Table 5) show an increase in the number of academic/research institutes from $27 \%$ in 2005 to $44 \%(15)$ in 2008 . This indicates that their has been an increased enthusiasm shown by these institutions. This was a factor which was highlighted at the ACCMT workshop that was held in October 2005. This increase is also shown clearly in the Table 6 which reflects that the practice is mostly taken up for education and research.

The number of personnel engaged in Geoinformatics applications has risen from an estimated 223 to 1286 showing a marked increase. This could be attributed to the increased number of organizations having a large number of persons involved in GPS related activities such as positioning and field data collection. The era of 2005-2008 also indicated a liberal approach towards GPS use along with the prices becoming affordable to many agencies. These could also be the reasons for the increase number of personnel reflected in the questionnaire survey.

Even though the number of Geoinformatics practicing agencies may not appear to have increased as one would expect, the number of persons involved clearly show the consolidation of the practice of Geoinformatics within those agencies.

3. The results indicate that the applications within the agencies have a wide variation. However, the tasks carried out using Geoinformatics, still appear to concentrate in map making or other less complex 
computational activities. This is similar to the observation that had been made in the year 2005. The number of agencies carrying out advanced GIS work also has increased. The increased number of map making and database preparation efforts on one hand indicates that these agencies are just stepping in to the arena and therefore the majority of agencies carrying out map making would only be a passing scenario. On the other hand there are map making agencies which are also expanding their activities and this result may be reflecting such effects. However from these results, decision makers should also be able to identify a potentially threatening situation where there exists a lack of data sharing or reasonable data pricing which drives or compels users to spend or waste considerable amount of time for data preparation. This parallel efforts for map making by various organizations also leads to another problem which is the lack of consistency thereby leading to quality concerns.

4. The proprietary software use in Sri Lanka is dominated by the ESRI. A majority of users work with either ArcGIS or Arc View (Figure 6). There appears a user community for open source software which is a sign that may need to be explored further for the promotion of appropriate tools. Hardware and equipment do not appear as an issue for the running of application software. However, peripheral support such as plotters, digitizers etc., does not appear as adequate. Decision makers would require to look into the hardware requirements in order to ensure sound functioning of Geoinformatics applications.

\subsection{Commitment}

Organizational commitment which is a reflection of the recognition of a separate division through the provision of a divisional structure and finances, along with the identification of suitable resource persons enabling good quality outputs, and facilitating with licensed software, is in general assumed as low in the academic, research or training organizations when compared with the executing or regulating agencies (Figure 9). Only four from the former group have reached a status corresponding to a commitment status value greater than $40 \%$, while 11 agencies from the latter have achieved this level. Most organizations indicated a lesser commitment in the area of remote sensing while in general GIS and GPS are recognized in a similar manner. The reason for remote sensing to fall behind can probably be due to lack of remote sensing knowledge within the agency or due to the fact that the agency objectives does not require to work with remote sensing imagery. The agencies with higher values have separate divisions and are well supported by the agencies by making provisions to utilize external resource personnel. Only a very limited number of agencies have received separate funding for Geoinformatics applications.

\subsection{Readiness}

Organizational readiness to perform Geoinformatics applications was assessed with the present involvement, type of work that had been executed, availability of equipment and availability of capable staff for Geoinformatics applications. The indicator values pertaining to the surveyed agencies indicated a superiority in the academic, research and training organizations when compared with the rest (Figure 10). 11 out of 16 Academic, Research and Training organizations are having an indicator value greater than $40 \%$, whereas only 11 out of 20 Executing or Regulating Organizations have $a$ value greater than $40 \%$ for the Readiness indicator. In general the readiness for GIS applications are much stronger compared to RS and GPS. GPS readiness is the weakest in almost all agencies. The results indicate the need to strengthen the organizations with suitable human resources and also with sufficient equipment to ensure a high ranking.

\subsection{Competence}

The competence to carryout Geoinformatics applications was assessed with the availability of trained staff both through structured training programmes and through on the job training. Assessments indicated that the surveyed agencies are generally weak in this aspect (Figure 11). Number of agencies falling in the low region of the indicator range is 8 out of the 
total of 36 agencies. Competence indicator consisted of a score from the availability of competent persons which carried a weight of 2 cver the 1 given to others. This emphasizes the fact that an agency needs to possess competent persons to achieve the competence to perform Geoinformatics applications. This methodology of assessment has shown the inadequate level of well educated and experienced staff in most of the organizations.

\subsection{Experience}

Results obtained for the organizational experience indicator is shown in the Figure 12 From the results it is clear that only 3 out of the 36 agencies are with a status percentage satisfying a high rank. There are another five agencies that fall in the high side of the Medium rank. Rest of the organization are having a low or low medium rank with respect to the project experience which is estimated by the publications, international, regional or national experience, and training/teaching capabilities. The responding agencieis had not contributed with sufficient data for the questions pertaining to this section. One reason would be the poor documentation of the projects activities and a lack of scientific work worthy of technical publications. This has to be encouraged in the country in order to promote accurate, quality Geoinformatics applications. It was also felt that having experience with a wider audience enables the working and work organizing capabilities of a particular entity. This was considered as an important factor in the assessment of work experience. This was indicated by only three agencieis and they have scored above the rest. It is important to encourage agencies to commence at least collaborative national/international works so that the status of the Geoinformatics applications could be elevated with sufficient project exposure. Many organizations except academic, and teaching agencies had not indicated the experiences in conducting training programmes. It is necessary to encourage Geoinformatics divisions of all organizations to undertake not only training of external personnel but also internal staff so that they would be gaining self confidence, arhieving quality, and finding justifications needed for work demonstrations, and also contributing to the nation's Geoinformatics critical masses.
These aspects appeared lacking the data received at the survey of practicing agencies.

\subsection{GAS}

The overall indicator of Geoinformatics Applications Strength (GAS), which was computed by simple aggregation and averaging the component indicators, shows that most of the organizations are in the lower medium rank, whereas only one academic agency and two industry agencies are in the high range with respect to the Threshold desired for Geoinformatics applications. There are about ten agencies in the near vicinity of high GAS levels. Almost all the agencies are showing a balanced approach in the three main components namely G1S, RS and GPS. The GAS levels of agencies reflect the relative position of each agency and the components reflect the areas of strengths and weaknesses therefore it is felt that these indicators would be extremely helpful for decision makers both in the agencies and at national level to achieve a status which would lead to efficient and rational spatially distributed resource management. Future improvements to the GAS components includes an addition of a sub indicator for data standards and quality flagging of Geoinformatics products.

\subsection{Data Quality}

The data capturing efforts did not attempt to capture data on the status of data standards adopted, quality control methods, and verification techniques. It was not included to avoid unnecessary concerns that would arise during data collections. However, this has to be incorporated in the data collection attempts for a similar survey in the future. The national policy development activities and also the common knowledge has revealed that as at present there are only a few efforts to ensure accurate outputs. Since many agencies are preparing their own databases and then utilize them for different objectives which are mostly for planning purposes, as at present, this detail does not appear as a major factor except at the academic and research environments. However with the number of organizations increasing and then the nation is attempting to reach for a critical mass, it is now a necessity to commence action on the data standards and quality, 
Table 7 : Task involvement

\begin{tabular}{|l|c|}
\hline \multicolumn{1}{|c|}{ Task } & $\begin{array}{c}\text { No. of } \\
\text { Organisations }\end{array}$ \\
\hline Map Preparation & 29 \\
Overlay Operation & 20 \\
Image Analysis & 24 \\
Network Analysis & 7 \\
3D Analysis & 15 \\
Spatial Analysis & 22 \\
Other & 9 \\
\hline
\end{tabular}

probably through a National apex body. An attempt was made to identify the availability of geo information standards in the country for referencing, through an inquiry made the libraries in the country for the availability of either the 'ISO/TC 211 Geographic Information Standards' or a similar set of documents but turned out as negative. In this back drop it may be necessary for the state to now step in to have appropriate mechanisms for driving the Geoinformatics trend in the correct direction.

\subsection{Overall}

The study analysis revealed a relative measure of agencies with reference to a desired threshold status for sound Geoinformatics application status. This pointed to the needs of the commitment, both national and organizational, the readiness of agencies, the competence and the work experiences. Also the survey results and background information through available literature indicates the need of a spatial data infrastructure and a sound overarching policy. During the survey it was noted that future surveys can be made more quantitative, given the present status of national organizations. This would enable establishing clear value ranges for the classification of status components into very high, high, medium or low.

The status survey pointed to the requirement of recognizing the need for guided work execution through experienced personnel, incorporation of structured training programmes to an organization's work programme so that the organization will be in touch with this cutting edge technology practice, allocation of separate divisions and finances, and making attempts to increase the critical mass of practicing population in the country. This points to the need of introducing the map based thinking early in the lives of children and probably the nation could adopt from the US National Academy of Science report on K-12 GIS education cited earlier (NAS 2006).

\section{Conclusions}

1. The study identified that the Geoinfomatics applications in Sri Lanka is carried out only in about 40 agencies and that the software widely used is either ArcGIS or Arc View

2. Geoinformatics Applications and the Practice is almost equally practiced in the academic and research agencies and also at Executing and Regulating Agencies

3. Majority of the organizations carryout GIS and Remote Sensing activities while a significant section is executing applications related to GPS.

4. Many National Agencies did not have separate units for Geoinformatics applications, nor did they have clear cut budget allocations.

5. Number of trained professionals in the country is limited and the survey results lead to the need to strengthen the training and education in Geoinformatics applications.

6. The overall indicator for Geoinformatics Application Status (GAS) defined in the study with four components namely, commitment, readiness, competence and experience enabled an easy assessment of GAS levels pertaining to each organization

7. Component surveys indicated the need to enhance the organizational commitment through appropriate resource persons, while enhancing the competence and enabling an environment to enhance wider experiences.

8. Study did not include the Quality of outputs and the use of spatial data standards, since it is felt as something that has to be achieved in the near future. This has to be included as a component indicator for future status surveys.

\section{Acknowledgement}

The authors wish to thank the Arthur C Clarke Institute for Modern Technologies and the University of Moratuwa for the support extended for this study. Prof. KKYW Perera, 
Prof. (Mrs) Indra Dayawansa, Eng Sanath Panawennage are especially thanked for the encouragement given throughout the study. The support extended by the ICGAT and its staff are acknowledged.

\section{References}

1. Crompvoets and Bregt 2003 Joep Crompvoets and Arnold Bregt, "World Status of national Spatial Data Clearinghouses", URISA Journal , Vol. 15,APA I , 2003

2. UNESCO "Developing and Using Indicators of ICT use in Education", United nations Educational Scientific and Cultural Organization , UNESCO Bangkok

3. UNESO 2006 "Questionnaire for Inventory 2006 on Space Technology Application Capabilities, Facilities and Activities in Asia and the Pacific region", United Nations Economic and Social Commission for Asia and the Pacific, Inventory 2006

4. Menou 1993 Michel J. Menou, "Measuring the Impact of Information on development", International Development Research Centre 1993

5. Wijesekara 2005 Wijesekara, N.T.S., "Spatial Resource Planning and Management Applications in RS/GIS and present day needs, Proceedings of the Workshop on Remote Sensing/GIS for Environmental Monitoring and Spatial Resource Management, Arthur C Clarke Institute for Space Technology, Katubedda, Moratuwa, October 2005

6. Dayawansa and De Silva 2005 Dayawansa, N.D.K., and De Silva, R.P., "Applications of Remote Sensing in Environmental Monitoring", Proceedings of the Workshop on Remote Sensing/GIS for Environmental Monitoring and Spatial Resource Management, Arthur C Clarke Institute for Space Technology, Katubedda, Moratuwa, October 2005

7. Jayatilaka 2005 Jayatilaka, S., "Capacity Building Needs in Sri Lanka for the use of GIS and Remote Sensing Technologies", Proceedings of the Workshop on Remote Sensing/GIS for Environmental Monitoring and Spatial Resource Management, Arthur C Clarke Institute for Space Technology, Katubedda, Moratuwa, October 2005

8. Bandara 2005 Bandara, K.R.M.U., "Incorporation of RS \& GIS in Education Curricular for Environmental Monitoring", Proceedings of the Workshop on Remote Sensing/GIS for Environmental Monitoring and Spatial Resource Management, Arthur C Clarke Institute for Space Technology, Katubsdda, Moratuwa, October 2005
9. De Silva 2008 De Silva, R.P., "GIS and Geoinformatics in Sri Lanka", GIS@ development, Arthur C Clarke Institute for Space Technology, Katubedda, Moratuwa, March 2002, http://www.gisdevelopment.net/ magazine/gisdev/2002/mar/ggsl.shtml, visited in May 2008

10. Wijesekera 2008 Wijesekera, N.T.S., National Policy on the Use of Spatial Data; Feature Article, National News Paper, The Sunday Observer, , 22nd June 2008,

11. MNBEID 2008 Ministry of Nation Building and Estate Infrastructure Development, and the Ministry of Land and Land Development, National Policy on the Use of Spatial Data, http:/ /www.mnbd.gov.lk/downloads/policy/ policy\%20e.pdf(English), visited 9th June 2008.

12. NAS 2007National Academy of Sciences, A Research Agenda for Geographic Information Science at the United States Geological Survey, National Academies Press, ISBN 0-309-11155-2, Washinton DC 20001, 2007

13. NAS 2006National Academy of Sciences, Learning to Think Spatially: GIS as a Support System in the K-12 Curriculum, National Academies Press, ISBN 0-309-53191-8, Washinton DC 20001, 2006

14. Wikipedia 2008 "Geoinformatics", The Free Encyclopedia, May 12th, 2008, http:// en.wikipedia.org/wiki/Geoinformatics)

15. ESRI 2008Application of GIS Technology, http:/ /www.esri.com/industries.html, Visited 12th May 2008

16. Albert K.W. Yeung, Concepts and techniques of Geographic Information Systems, Indian reprint ed, Ontario Police college, Aylmer, Ontario, Canada, 2005, pp. 242-248, pp. 405-414, pp. 233241, pp. 377-381, pp. 434-436

17. Rhind et al 2001 Geographic Information Systems and Science

18. Menou 1993 Menou, M.J., Measuring the Impact of Information on Development, International Development Research Center, Ottawa, ON, Canada, 1993, http://www.idrc.ca/openebooks/ 708-6/pdf2xml, visited on 2nd June 2008.

19. Gartner (2002) U.S. Public-Sector GIS Survey: Key Issues and Trends, Gartner's 2002 U.S. Public-Sector Geographic Information System Survey, http://ontogeo.ntua.gr/nagii/ US_Public-Sector_GIS_Survey.pdf, visited in May 2008 